\title{
The Role of Cold Working in the Creep Deformation of Nb Stabilized Stainless Steel. II. Creep Equations
}

\author{
E. Evangelista ${ }^{1}$, C. Guardamagna ${ }^{2}$, L. Kloc ${ }^{3}$, A. Rosen $^{4}$ and S. Spigarelli ${ }^{1}$ \\ 'Department of Mechanics, University of Ancona, 1-60131 Ancona, Italy \\ ${ }^{2}$ ENEL CRAM, Via Monfalcone 15, I-20132 Milano, Italy \\ ${ }^{3}$ Institute of Physics of Materials, Brno, Czech Republic \\ ${ }^{4}$ Department of Materials Engineering, Technion, Haifa 32000, Israel
}

\begin{abstract}
The development of the microstructure during creep of a cold worked AISI 347 stainless steel was investigated in order to produce a phenomenological model of transient deformation. It was proposed that the number per unit volume of mobile dislocations was a linear function of the free dislocation density $\rho$; furthermore, it was assumed that also the average velocity of the line defects was a function of the free dislocation density. The resulting creep equation was able to give an acceptable simulation of recoverycontrolled creep strain; furthermore, the model was used to describe the free dislocation density evolution as well as the variation of the mobile dislocation fraction with time. These results were explained in terms of a particle hardening effect due to the fine $\mathrm{NbC}$ that nucleated on dislocations during the test.
\end{abstract}

\section{INTRODUCTION}

The time-dependent deformation and the microstructural evolution during high temperature transient creep were extensively studied in the past $/ 1-6 /$; in Class $M$ metallic materials (i.e., pure metals and single-phase alloys) the development of heterogeneous microstructure is accompanied by a continuous decrease of strain rate (normal primary creep). The dislocation distribution becomes more and more inhomogeneous as deformation proceeds, leading to well-defined subgrain boundaries and regions which are almost dislocation-free $/ 1,2 /$. The total dislocation content $\rho_{\mathrm{T}}$ grows during primary creep, but this increase is associated exclusively with the development of a subgrain structure $/ 4,6 /$. On the other hand, the free dislocation density $\rho$ (dislocation content inside subgrain) continuously decreases during normal primary creep. In Class A metallic materials (solid solution alloys) the free dislocations glide in a viscous manner due to the presence of solute atoms $/ 5 /$; furthermore, the presence of solute atmospheres also influences the shape of the transient curve, leading to the onset of a pseudo-tertiary creep at low stresses, while the microstructure is often characterized by a fairly homogeneous dislocation distributions.

The austenitic stainless steel creep response shows in general a relatively long normal primary stage accompanied by the formation of well-defined substructures $/ 7-10 /$, although the precipitation of fine $\mathrm{M}_{23} \mathrm{C}_{6}$ (where $\mathrm{M}$ is a metal) on dislocations has been observed after a long time of exposure $17 /$. Several models have been proposed in order to describe the recovery-controlled (i.e., $\rho$ decreasing with time) transient creep deformation in these materials, and a large part of the theories related the creep deformation to the evolution of the free dislocation density. The network models, for example, associated the decrease in creep rate typical of normal primary creep with the formation of a network of dislocations /8-12/; another theory was 
developed to rationalize the effect of prestrain in the shape of the creep curve /13-17/. The imposing of a previous cold work in a simple austenitic steel (for example, AISI 304) before creep, leads in fact to a strong reduction of the extent of the normal primary creep, or even to the onset of pseudo-tertiary creep 14,16,17/; hence, Ajaja and Ardell simulated the transient creep behaviour of the as-received as well as prestrained AISI 304 by taking into account the strain generated during annihilation of dislocations.

A further family of creep theories was developed in order to describe transient and secondary creep in particle ( $\mathrm{TiC}$ or $\mathrm{NbC}$ ) reinforced stainless steels /1820/; the particle strengthening effect of $M X$ precipitates (in which $\mathrm{M}$ is a metal, mainly $\mathrm{Nb}$ or $\mathrm{Ti}$ in these materials, and $\mathrm{X}$ is typically $\mathrm{C}$ ) was often invoked to explain the high creep strength of $\mathrm{Nb}$ or $\mathrm{Ti}$ added materials $/ 21-24 /$, such as $20 \mathrm{Cr}-25 \mathrm{Ni}-\mathrm{Nb}$ or $20 \mathrm{Cr}$ $25 \mathrm{Ni}-\mathrm{Ti}$, so that Ecob described the steady state creep by the equation:

$$
\epsilon_{m} \propto\left(\rho-\rho_{0}\right)^{2.5}
$$

where $\dot{\varepsilon}_{\mathrm{m}}$ was the minimum creep rate, $\rho$ was the dislocation density inside subgrains, $\rho_{0}$ was a threshold dislocation content (annealed in or irrecoverable dislocation density) that could be calculated as $\rho_{0} \approx(\sigma$ $\left.\mathrm{OR} / \alpha^{\prime} G b\right)^{2}, \sigma_{\mathrm{OR}}$ being the Orowan stress generated by the particle distribution, $\alpha^{\prime}$ a parameter of the order of unity, $G$ the shear modulus and $b$ the Burgers vector /18-20\%. On this basis an interesting attempt to describe forward creep in AISI 347 stainless steel after a $750^{\circ} \mathrm{C}$ x $200 \mathrm{~h}$ aging was developed by Senior /24/ who obtained the equation:

$$
\dot{\epsilon}_{n} \alpha\left\langle\sigma-\sigma_{0}-\alpha^{\prime \prime} G b\left(\rho_{T}-\rho_{0}\right)^{1 / 2}\right\rangle^{3}
$$

where $\sigma_{0}$ was the threshold stress related to the characteristic of the particle dispersion /6/, $\rho \mathrm{T}$ was the total dislocation density, $\alpha$ " a geometrical factor, and $\rho_{0}$ was the irrecoverable dislocation density as previously defined by Ecob. It must be pointed out that the main task of $\mathrm{Nb}$ addition in the AISI 347 is to prevent precipitation of $\mathrm{Cr}_{23} \mathrm{C}_{6}$ carbides, avoiding the depletion of $\mathrm{Cr}$ from the matrix; nevertheless the fine distribution of particles produced by the precipitation of $\mathrm{NbC}$ is thought to have an additive strengthening effect /22$24 \%$

The aim of this work is to rationalize the effect of cold working (c.w.) on the shape of the transient creep in AISI 347 stainless steel, and to produce a simple phenomenological creep equation.

\section{MATERIAL AND EXPERIMENTAL}

The material used in this study was AISI 347; the steel was supplied in the form of extruded tubes in a solution-treated condition $\left(1120^{\circ} \mathrm{C}-45 \mathrm{~min}\right)$ and had the following chemical composition (\%): $17.3 \mathrm{Cr}, 10.4 \mathrm{Ni}$, $0.048 \mathrm{C}, 0.52 \mathrm{Nb},<0.01 \mathrm{Ta}, \mathrm{Fe}$ balance. The experimental procedure has been described in detail in the companion paper $/ 25 /$.

\section{RESULTS}

Fig. 1 illustrates a qualitative description of the trend of the dislocation density during creep as observed at $650^{\circ} \mathrm{C}-157 \mathrm{MPa}$; Table 1 lists the results of the quantitative evaluation of the microstructural evolution during creep for the solution-treated (as received, a.r.), and cold worked (c.w.) samples under the same test conditions. The free dislocation density $\rho$ increased between 0 and $120 \mathrm{~h}$, approaching a

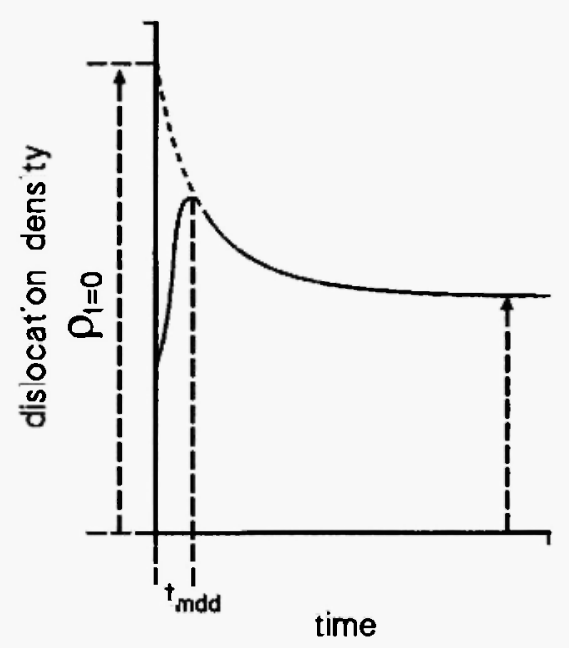

Fig. 1: Qualitative description of the trend of dislocation density $650^{\circ} \mathrm{C}-157 \mathrm{MPa}$. 
Table 1

Microstructural features obtained from interrupted tests at $650^{\circ} \mathrm{C}-157 \mathrm{MPa}$.

\begin{tabular}{cccc}
\hline c.w. & time $[\mathrm{h}]$ & $\rho\left[10^{14} \mathrm{~m}^{-2}\right]$ & $\mathrm{N}_{\mathrm{v}}\left[10^{21} \mathrm{~m}^{-3}\right]$ \\
\hline 0 & 24 & 2.04 & 0.04 \\
& 120 & 2.62 & 0.5 \\
& 600 & 1.00 & 0.29 \\
\hline 5 & 24 & 3.52 & 0.1 \\
& 120 & 4.58 & 0.6 \\
& 600 & 2.52 & 0.8 \\
\hline \multirow{2}{*}{15} & 24 & 4.27 & 0.4 \\
& 120 & 5.43 & $>0.9$ \\
& 600 & 4.46 & $>1.1$ \\
\hline \hline
\end{tabular}

maximum value that was obtained at $t=t_{m d d}$ ( $t_{\text {mdd }}$ being the time at which the dislocation content reached its peak, Fig. 1); between $120 \mathrm{~h}$ and rupture the dislocation density dropped. It is clear that the general trend was a strong increase in dislocation content during the very early stage of creep deformation, followed by a decay in $\rho$ (recovery-controlled creep).

Another important feature that can be observed /25/ is the intragranular precipitation of fine $\mathrm{NbC}$; these fine particles (between 5 and $80 \mathrm{~nm}$ ) nucleated heterogeneoushy on dislocations during the high temperature (creep or aging) exposure $126,27 /$. The number per unit volume and the size of the particles increased between 0 and $120 \mathrm{~h}$; Fig. 2 shows the trend of $\mathrm{N}_{\mathrm{v}}$ measured on the samples tested at $650^{\circ} \mathrm{C}$ and $157 \mathrm{MPa}$; in the as received material the coarsening was detected between 120 and $600 \mathrm{~h}$. In the $5 \% \mathrm{c.w}$. the number of particles increased at least up to $600 \mathrm{~h}$, and the coarsening appeared only after a long time ( $t>600 \mathrm{~h})$ of exposure. It is worth noting that the amount of $\mathrm{NbC}$ precipitated after $120 \mathrm{~h}$ in the a.r. sample was quite close to that in the $5 \%$ c.w. In the $15 \%$ c.w., the size of the particle was very fine $(5-10 \mathrm{~nm})$, and the high dislocation density made it difficult to detect the particles, which led to a probable underestimation of $N_{v}$; nevertheless, the measured $N_{v}$ after $120 \mathrm{~h}$ is close to $1 \times 10^{21} \mathrm{~m}^{-3}$, and the size of the particles did not show any large increase between 120 and $600 \mathrm{~h}$. The experimental points recorded at $650^{\circ} \mathrm{C}-157 \mathrm{MPa}$ are reported in Fig. 3 ; the as received sample underwent a very short stage of strongly decreasing strain rate, followed by a stage of an almost constant (slightly increasing) creep rate. The strain-time behaviour of the prestrained sample is completely different: after a relatively short (about 50 h) stage of a rapidly decreasing creep rate, a second stage of a slower decrease in creep rate follows. A

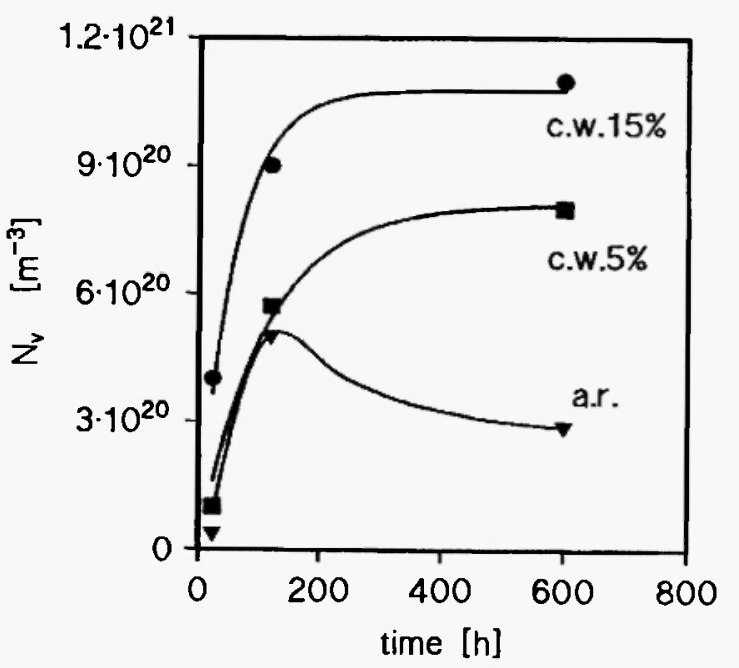

Fig. 2: Evolution of number of particles per unit volume at $650^{\circ} \mathrm{C}-157 \mathrm{MPa}$. 

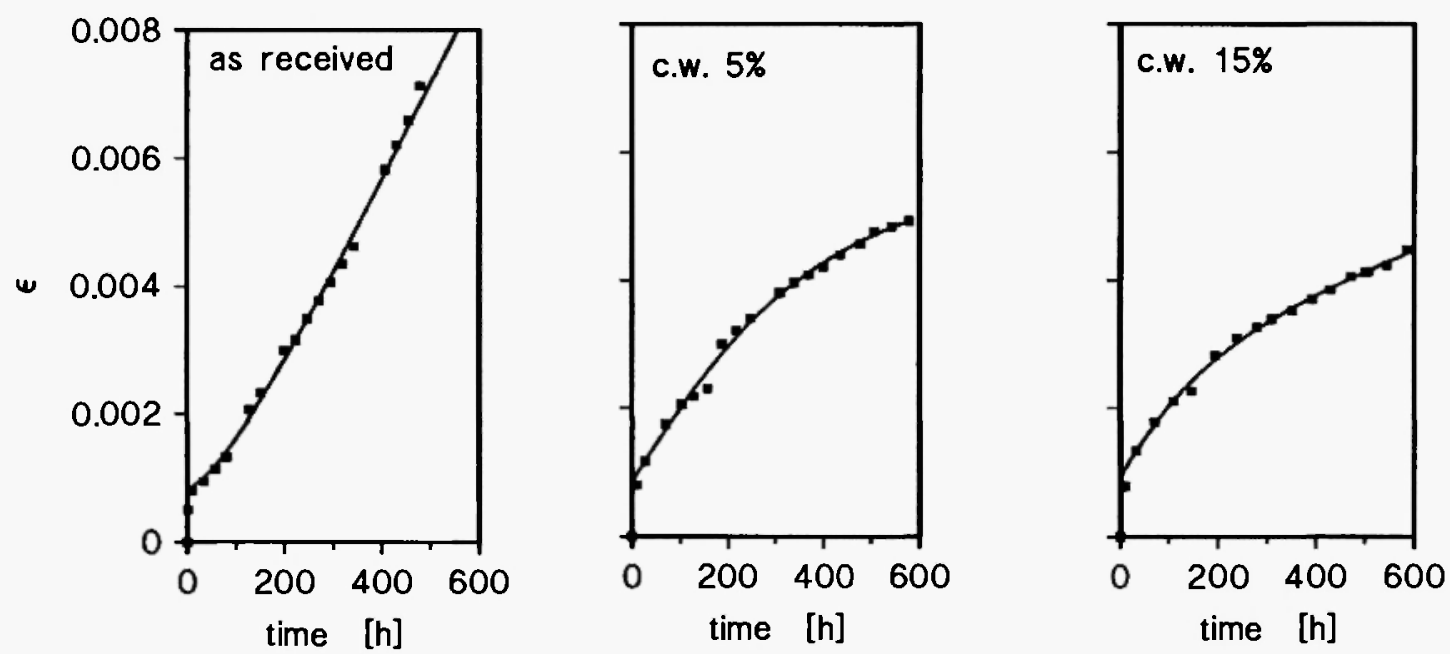

Fig. 3: Creep curves obtained from the best fit of experimental data through Eqn. $11\left(\mathrm{~T}=650^{\circ} \mathrm{C}-157 \mathrm{MPa}\right)$.

similar effect of cold working amount on the shape of the creep curves was observed under quite different test conditions (for example, $625^{\circ} \mathrm{C}-196 \mathrm{MPa}$ or $725^{\circ}-127$ $\mathrm{MPa}$ ).

\section{DISCUSSION}

\section{a) Creep Curve}

Following Ajaja and Ardell $/ 16 /$, who derived this assumption from Johnston and Gilman /28/, Li /29/ and Akulov $130 /$, the rate of change in free dislocation density from $\mathrm{t}_{\mathrm{m} d d}$ up to $600 \mathrm{~h}$ could be approximated by the equation

$$
\rho=k \rho-k^{\prime} \rho^{2}
$$

where $k$ and $k^{\prime}$ are the multiplication and annihilation rate constants, respectively, which, in the first instance, were assumed to be dependent on stress, temperature and amount of cold working (nevertheless, it must be pointed out that a time dependence, at least for $k^{\prime}$, was found to exist by Ajaja /17/). After a relatively long time of creep exposure, at $t=t_{s}$, the dislocation density would attain the constant value $\rho=\rho_{s}$, and $\partial \rho / \partial t=0$, so $k^{\prime}=k / \rho_{\mathrm{s}}$. Integration of Eqn. 3 yields

$$
\rho=\rho_{S}\left[1-\frac{\rho_{t=0}-\rho_{s}}{\rho_{t=0}} \exp (-k t)\right]^{-1}
$$

where $\rho_{t=0}$ is the initial (apparent) dislocation density. Eqn. 4 could be used to describe the decrease in dislocation density between $t_{\text {mdd }}$ and the rupture (recovery-controlled creep), while it fails in describing the initial increase in dislocation content. Taking $\Theta(t)$ $=1-\beta \exp (-k t)$, where $\beta=1-p_{s} / p_{t=0} / 16 /$, Eqn. 4 can be rewritten as:

$$
p=\frac{\rho_{s}}{\theta}
$$

The trend in dislocation density during the first stage of the primary creep ( $t<t_{\text {mdd }}$ ) has not been completely investigated, and no correlation between the microstructural parameter and the creep rate was attempted. On the other hand, from the results previously reported it is obvious that the creep deformation between 100 and $600 \mathrm{~h}$ was controlled by the recovery of the dislocation structure. In this study it was assumed that the creep rate during recoverycontrolled (primary as in c.w. samples, or tertiary as in a.r.) creep could be described by the classical TaylorOrowan equation

$$
\dot{\epsilon}=\alpha \rho_{m} b V
$$

where $b$ is the Burgers vector, $\rho_{m}$ is the number per unit volume of mobile dislocations, $v$ is their average velocity, $\alpha$ is a geometrical factor. The density of mobile dislocations can be expressed as $\rho_{m}=\rho-\rho_{i}$, 
where $\rho$ is the measured free dislocation density, and $\rho_{i}$ is the fraction of the dislocation population that is immobile, due to dislocation interaction (Taylor hardening) or particle pinning. The following empirical equations were used to estimate $\rho_{i}$ and $v$ dining recovery-controlled creep:

$$
\begin{gathered}
\rho_{i}=B \rho+C \\
v=A \rho^{-m}
\end{gathered}
$$

where $A, B$ and $C$ were assumed to depend on stress and temperature, in addition to c.w. As shown by Ajaja and Ardell $/ 15,16 /$, when $\mathrm{m}>0$, Eqn. 8 is consistent with the expectation that the average mobility of the dislocation increases when dislocation density drops. The Taylor-Orowan equation is therefore rewritten

$$
\varepsilon=\alpha b A\left(B_{0} \rho-C\right) \rho^{-m}
$$

where $B_{0}=1-B$; by substituting $\rho=\rho_{\mathrm{s}} / \Theta$, the above equation yields:

$$
\dot{\boldsymbol{\epsilon}}=\alpha b A\left(\frac{B_{0} \rho_{S}}{\theta(t)}-C\right)\left(\frac{\rho_{S}}{\theta(t)}\right)^{-m}
$$

In order to obtain a simple creep equation, the $A ., B$ and $C$ parameters were considered to be independent of time (or deformation); a preliminary least squares analysis of the experimental $\varepsilon_{\mathrm{m}-\mathrm{t}}$ data between 120 and $600 \mathrm{~h}$ at $650^{\circ} \mathrm{C}-157 \mathrm{MPa}$ gave $\mathrm{m}=1.5$. Taking $\mathrm{m}=$ 1.5 , the integration of Eqn. 10 results in the creep equation:

$$
\begin{aligned}
\epsilon=\left(\frac{\alpha b A C \rho_{s}^{-1.5}}{k}-\frac{\alpha b A B_{0} \rho_{s}^{-0.5}}{k}\right) & {\left[2 \theta^{0.5}+\ln \left(\frac{\left|\theta^{0.5}-1\right|}{\theta^{0.5}+1}\right)\right]+} \\
& +\frac{\alpha b A C \rho_{s}^{-1.11}}{k}\left(\frac{2}{3} \theta^{1.5}\right)+\epsilon_{p}
\end{aligned}
$$

where $\varepsilon_{p}$ is a constant adjusted to obtain the best fit of experimental data. The least squares analysis of the $\varepsilon-t$ points gave the best fit values of the parameters contained in Eqn. 11 (Table 2). Due to the very favourable comparison between the curves and the data shown in Figs. 3-5, Eqn. 11 could be regarded as an acceptable simulation of the recovery-controlled creep
Table 2

Best fit value of the parameters contained in Eqn. 11

$$
\left(\mathrm{T}=650^{\circ} \mathrm{C}-157 \mathrm{MPa}\right) \text {. }
$$

\begin{tabular}{ccccc}
\hline $\begin{array}{c}\rho_{\mathrm{s}} \\
{\left[\mathrm{m}^{-2}\right]}\end{array}$ & $\beta$ & $\begin{array}{c}k \\
{\left[\mathrm{~h}^{-1}\right]}\end{array}$ & $\begin{array}{c}\alpha b A C \\
{\left[\mathrm{~m}^{-3} \mathrm{~h}^{-1}\right]}\end{array}$ & $\begin{array}{c}\alpha b A B_{0} \\
{\left[\mathrm{~m}^{-1} \mathrm{~h}^{-1}\right]}\end{array}$ \\
\hline $1.22 \times 10^{14}$ & 0.98 & 0.0055 & $2.93 \times 10^{15}$ & 194.3 \\
$2.36 \times 10^{14}$ & 0.72 & 0.0034 & $1.09 \times 10^{17}$ & 460.7 \\
$4.27 \times 10^{14}$ & 0.54 & 0.0072 & $2.51 \times 10^{17}$ & 651.1 \\
\hline
\end{tabular}

deformation. The model, which gave a relationship relatively similar to that proposed by Ajaja and Ardell $/ 16 /$, was able to reproduce both primary or tertiary creep, but failed in describing the creep deformation of the very first stage of the tests (at $t=0$ the curves in Figs. 3-5 gave $\varepsilon>0$, which was physically unrealistic). Derivation of Eqn. 6, assuming that $A, B, C$ were timeindependent constants and $\mathrm{m}=1.5$, showed that in order to reproduce by Eqns. 6-8 a normal primary creep $(\partial \dot{\varepsilon} / \partial t<0)$ when the free dislocation content increased $(\partial \rho / \partial t>0)$, the condition $\rho>3 C / B_{0}$ had to be satisfied. By substituting the values of the parameter reported in Table 2, one could obtain that the above condition was not satisfied at $650^{\circ} \mathrm{C}-157 \mathrm{MPa}$. The implication of this analysis is that in the very early creep deformation, the dependencies of the $p_{i}$ and $v$ on the dislocation content were more complex than those regarded as valid during recovery-controlled creep. The formulation of Eqn. 6-8 is indeed very general, and one could expect that such relationships with proper values of the $A, B, C$ and $m$ parameters (that could even be functions of time or, more appropriately during strain hardening, of deformation), once the trend of dislocation content $\rho=$ $\rho(t)$ is known, could give an acceptable description also of the very fast initial normal primary creep. Unfortunately, as previously observed, the evolution of microstructure between 0 and $120 \mathrm{~h}$ was not completely investigated, making any further quantitative elaboration impossible. 

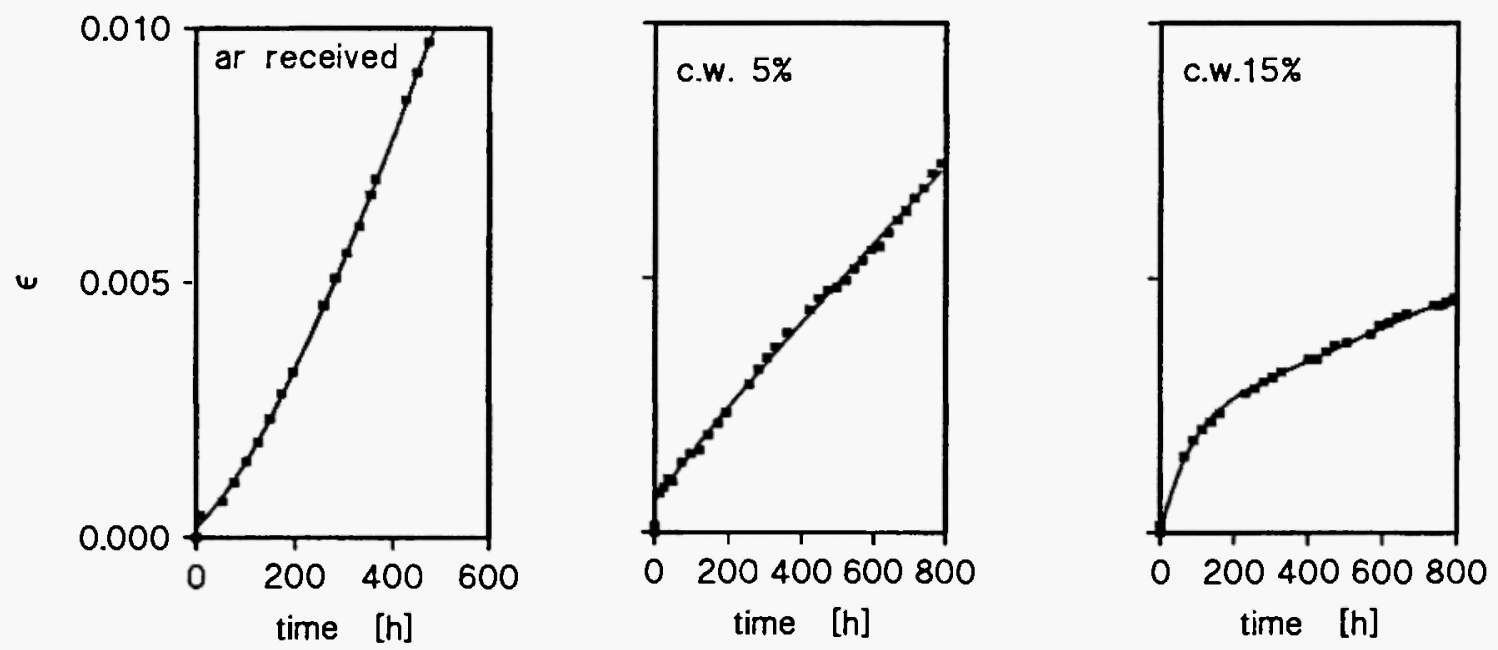

Fig. 4: Creep curves obtained from the best fit of experimental data through Eqn. $11\left(\mathrm{~T}=625^{\circ} \mathrm{C}-196 \mathrm{MPa}\right)$.
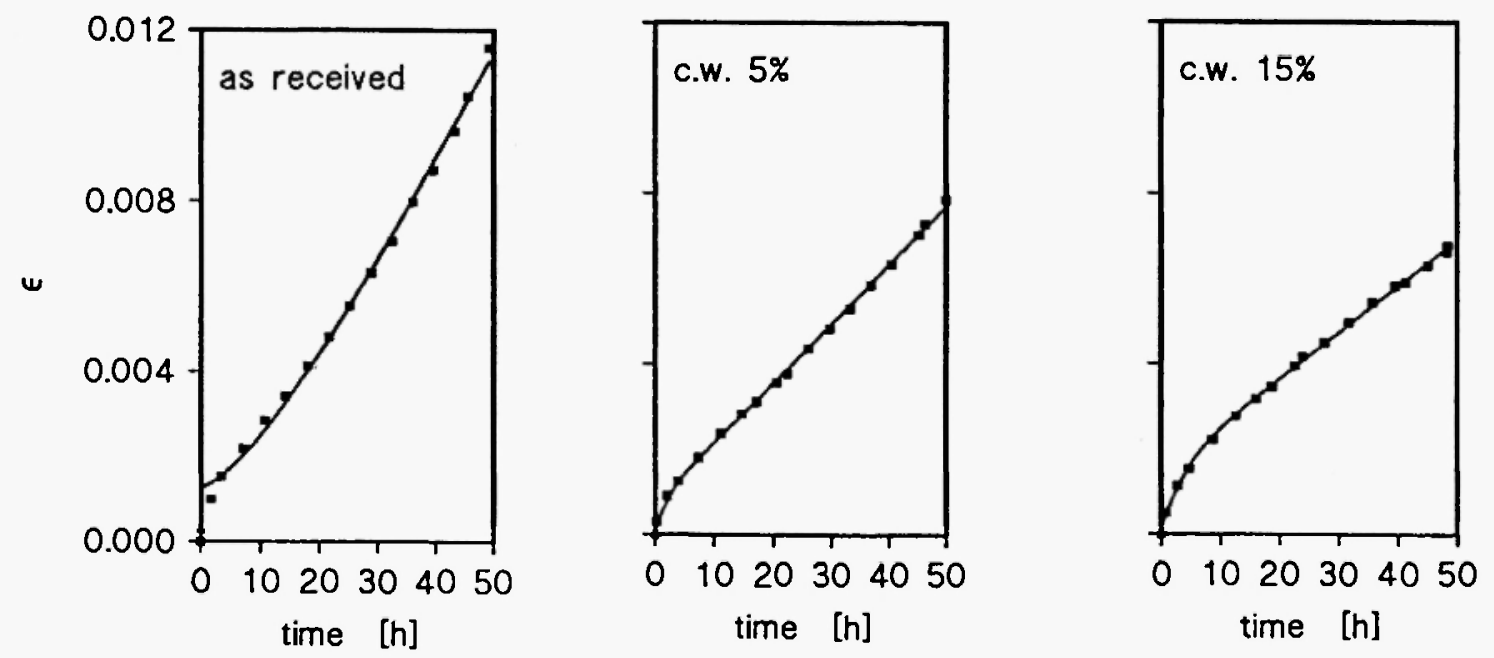

Fig. 5: Creep curves obtained from the best fit of experimental data through Eqn. $11\left(\mathrm{~T}=725^{\circ} \mathrm{C}-127 \mathrm{MPa}\right)$.

b) Effect of the Microstructural Evolution During Recovery-Controlled Creep on the Shape of the Creep Curve

Eqn. 11 contains a series of parameters $\left(A, B, C, \rho_{\mathrm{s}}\right.$, $k$ and $\beta$ ) whose dependence on the microstructure needs to be evaluated. $\rho_{\mathrm{s}}, k$ and $\beta$ could be related directly to the trend of dislocation density (Eqn. 4); at $650^{\circ} \mathrm{C}-157$ $\mathrm{MPa}, \rho_{\mathrm{s}}$ can be calculated by least squares analysis from the data in Table 1 by using for $k$ and $\beta$ the values in Table 2, yielding the $\rho$-t curves shown in Fig. 6; furthermore, the variation with time of the immobile dislocation content can be expressed as

$$
\alpha b A p_{1}=\alpha b A\left(1-B_{0}\right) \rho+\alpha b A C
$$

while the mobile dislocation density can be described by the equation

$$
\alpha b A \rho_{m}=\alpha b A B_{0} \rho-\alpha b A C
$$

Unfortunately, the data in Table 2 did not allow separation of the $B_{0}$ and $C$ variables, and the trend of the immobile dislocation density remained unknown. On the other hand, the $\rho_{m}$ variation (expressed as the fraction of the free dislocation that is mobile, i.e., as the $\alpha b A \rho_{\mathrm{m}} / \rho$ ratio) with time can easily be obtained from 


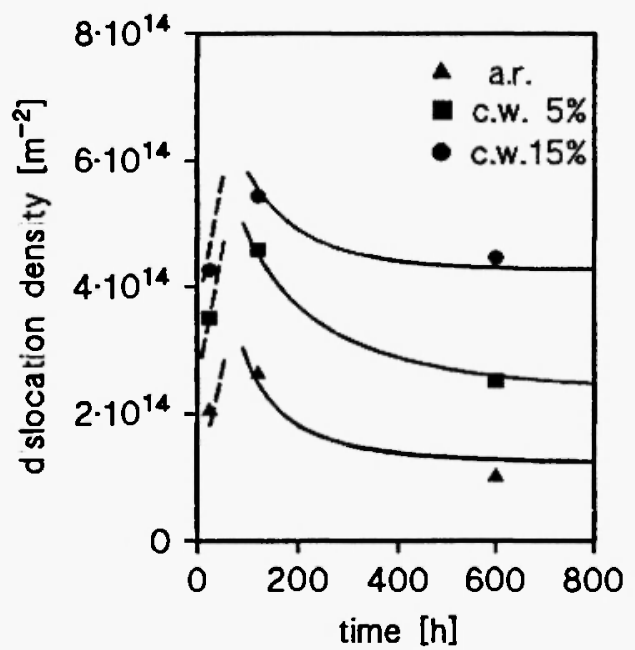

Fig. 6: Free dislocation density evolution during creep at $650^{\circ} \mathrm{C}-157 \mathrm{MPa}$; the solid lines represent Eqn. 4 as calculated from data in Tables 1 and 2, the dashed lines represent a purely speculative description of the early stage of dislocation evolution.

the data in Table 2 (Fig. 7). The curves in Fig. 7 show that, during recovery-controlled deformation in this steel, the fraction of the dislocations that was mobile decreased ( $A$ being time-independent). The 5 and 15\% prestrained materials showed almost the same

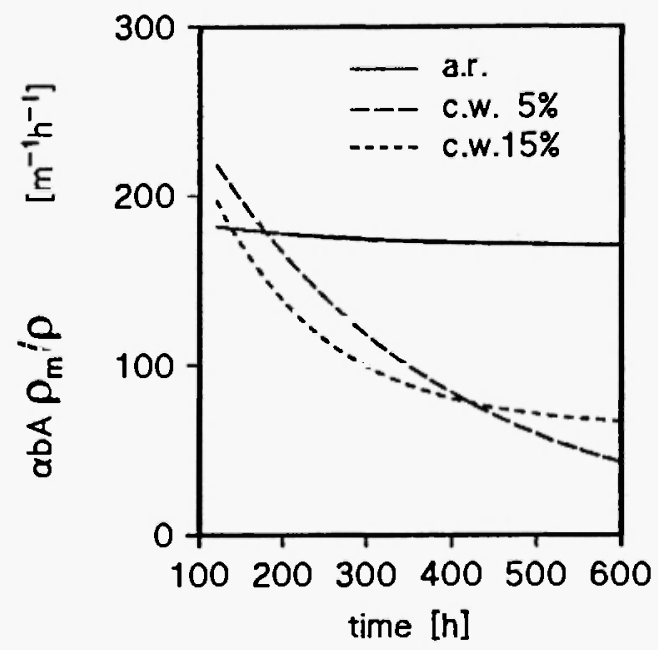

Fig. 7: Mobile dislocation density fraction as calculated from Eqns. 4 and 7 (data in Tables 1 and 2). The $\rho=p(t)$ equation for $t<$ $120 \mathrm{~h}$ is unknown, so that the figure shows only the trend for $\mathrm{t}>120 \mathrm{~h}$. behaviour (Fig. 7), with a strong decrease of the fraction of mobile dislocations; this effect could be related with the precipitation of fine carbides that reduced the mobility of the dislocations. TEM microscopy /16,25/ suggested that in the AISI 347 stainless steel the recovery processes were slower than in AISI $304 / 13-16 /$; in the $\mathrm{Nb}$-added steel, the precipitation of fine carbides nucleated on line defects reduced the mobility of dislocations by pinning and the effectiveness of the recovery processes. In the as received sample, the $\alpha b A \rho_{m} / \rho$ ratio stayed almost constant during the test and after $200 \mathrm{~h}$ was higher than in prestrained material. This high fraction of mobile dislocations in the a.r. sample could in turn be explained in terms of a reduced effectiveness of the particle strengthening mechanism, due to the large dimension and low number of dispersed $\mathrm{NbC}$.

An exactly opposite response to prestraining was found /13-16/ in AISI 304, in which cold working had the effect of reducing both the extent and the duration of primary creep. Moreover, prestraining up to $10 \%$ produced at $704^{\circ} \mathrm{C}-172.4 \mathrm{MPa}$ a pseudo-tertiary creep behaviour: Eqn. 11 was applied to the experimental curve reported by the author for this condition $/ 15 /$ and gave $k=0.000366, \beta=0.999$ (Fig. $8 \mathrm{a}$ ); subsequently $\rho_{\mathrm{s}}$ was calculated from the reported data of dislocation density evolution, and $\alpha b A \rho_{\mathrm{m}}$ was obtained. If Eqn. 11 is accepted, one can conclude that in the $10 \%$ c.w. AISI 304 tested at $704^{\circ} \mathrm{C}-172.4 \mathrm{MPa}$ the fraction of the mobile dislocations increased with time. This result could be explained by the absence of any significant precipitation of fine particles that did not obstruct the mobility of the defects. At the beginning of the test the high dislocation density produced a network that pinned a very large fraction of the total dislocation population. The recovery processes, on the other hand, reduced the effectiveness of the Taylor hardening; very well defined sub-boundaries were detected after $46 \mathrm{~h}$ at $704^{\circ} \mathrm{C}-172.4 \mathrm{MPa}$ in the $10 \%$ prestrained AISI 304 , while the microstructure of the AISI 347 after $260 \mathrm{~h}$ at $725^{\circ} \mathrm{C}-127 \mathrm{MPa}$ still revealed a relatively homogeneous distribution of dislocations. Ajaja and Ardell related /15/ the onset of a pseudo-tertiary creep to the formation of the substructure, and indeed the formation of sub-boundaries produces a dislocation-free subgrain interior (i.e., the few surviving free dislocations can move freely inside the subgrain). 

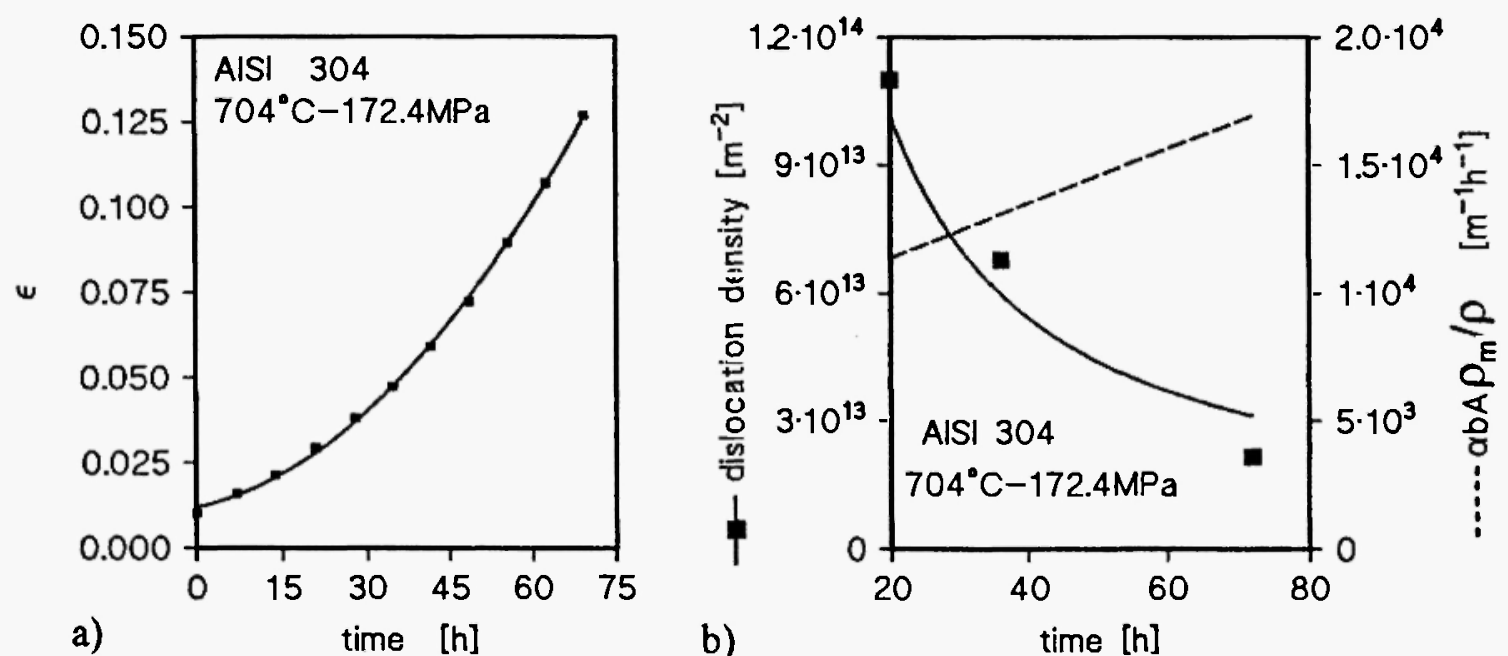

Fig. 8: a) Creep curve calculated for an AISI 304 prestrained up to $10 \%$ and tested at $704^{\circ} \mathrm{C}-172.4 \mathrm{MPa}$ (data from /15/); b) dislocation density and fraction of mobile dislocations $\alpha b A \rho_{\mathrm{m}} / \rho$; the symbols represent $p-t$ data from $/ 15 /$.

\section{CONCLUSIONS}

A phenomenological creep equation was proposed to rationalize the effect of cold working on the shape of the transient creep curve. The main assumptions on the basis of this equation were:

i) the dependence on time (or deformation) of annihilation and multiplication constants was neglected;

ii) the fraction of dislocation population that did not participate in the deformation, being pinned by particles or by other dislocations $\left(p_{i}\right)$, is a linear function of the free dislocation density;

iii) the mobility of dislocation is a power function of the free dislocation density, the exponent being $m$ $=-1.5$.

Integration of the resulting differential equation gave a relationship that was able to reproduce the part of primary creep that was recovery-controlled; the fraction of the total free dislocation density that was mobile, calculated through the model, decreased during the test. This decrease of the $\rho_{\mathrm{m}} / \rho$ ratio was attributed to the precipitation of fine $\mathrm{NbC}$ that obstructed the mobility of the dislocation.

\section{ACKNOWLEDGEMENTS}

The authors sincerely thank Dr. J. Stobrawa for his contribution to TEM microscopy and greatly appreciate the support of ENEL that partially funded this work under a research contract.

\section{REFERENCES}

1. T. Hasegawa, S. Karshima and R. Hasegawa, Metal Trans., 2A, 1449 (1971).

2. A. Orlova and J. Čadek, Phil. Mag., 28A, 861 (1973).

3. H.E. Evans and K.R. Williams, Phil. Mag., 25A, 1399 (1972).

4. H. Oikawa and T.G. Langdon, "The creep characteristics of pure metals and solid solution alloys", in: Creep Behaviour of Crystalline Solids, B. Wilshire and R.W. Evans (eds.), Swansea, U.K., Pineridge Press, 1985; p. 33.

5. W. Blum and B. Reppich, "Creep of particle strengthened alloys" in: Creep Behaviour of Crystalline Solids, B. Wilshire and R.W. Evans (eds.), Swansea, U.K., Pineridge Press, 1985; p. 137 
6. J. Cadek, Creep in Metallic Materials, Elsevier, 1988; p. 115.

7. S.R. Keown, "Microstructural changes occurring during the creep deformation of a simple austenitic steel at $600^{\circ} \mathrm{C}$, in: Proc. of Creep Strength in Steel and High Temperature Alloys, Sheffield, Iron and Steel Institute, 1972; p. 78.

8. M.E. Kassner, J. Mat. Sci., 25, 1997 (1990).

9. M.E. Kassner, Mat. Sci. Eng. A, 166, 81 (1993).

10. M.E. Kassner, A.K. Miller and O.D. Sherby, Metal Trans., 12A, 1977 (1982).

11. Shi Longquan and D.O. Northwood, J. Mat. Sci., 28, 5963 (1993).

12. Shi Longquan and D.O. Northwood, Acta Metall. et Mater., 41 (12), 3393 (1993).

13. O. Ajaja and A.J. Ardell, "The effect of prior cold work on the creep characteristics of AISI type 304 stainless steel", in: Proc. 4th International Conference on the Strength of Metals and Alloys, Nancy, France, Edit. Laboratoire Physique du Solide, E.N.S.M.I.M., I.N.P.L., Nancy, France, 1976; p. 880.

14. O. Ajaja and J. Ardell, Scripta Metall., 11, 1089 (1977).

15. O. Ajaja and J. Ardell, Phil. Mag. A., 39, 65 (1979).

16. O. Ajaja and J. Ardell, Phil. Mag. $A, 39,75$ (1979).

17. O. Ajaja, Scripta Metall. et Mat., 24, 1465 (1990).
18. R.C. Ecob, Acta Metall., 34, 257 (1986).

19. R.C. Ecob, Acta Metall., 12, 2149 (1984).

20. R.C. Ecob and H.E. Evans, Acta Metall., 4, 805 (1987).

21. J.A. Todd and Ren Jyh-Ching, Mater. Sci. Eng., A117, 235 (1987).

22. J.D. Cook, D.R. Harries and A.C. Roberts, "Some factors affecting the creep strength of $20 \% \mathrm{Cr}$ $25 \% \mathrm{Ni}-\mathrm{Nb}$ austenitic steel at $750^{\circ} \mathrm{C}$, in: Proc. of Creep Strength in Steel and High Temperature Alloys, Sheffield, Iron and Steel Institute, 1972; p. 91.

23. D.J. Powell, R. Pilkington and D.A. Miller, "The effect of prestrain on the creep and creep fatigue properties of a $20 \% \quad \mathrm{Cr}-25 \mathrm{Ni}-\mathrm{Nb}$ stabilized stainless steel", in: Proc. Second Inter. Conf. on Creep and Fracture of Engineering Materials and Structures, B. Wilshire and D.R.J. Owen (eds.), Swansea, U.K., Pineridge Press, 1984; p. 989.

24. B.A. Senior, Mater. Sci. Eng., A124, 159 (1990).

25. E. Evangelista et al., companion paper.

26. I. Ben-Haroe, A. Rosen and I.W. Hall, Mater. Sci. Tech., 9 (7), 620 (1993).

27. Y. Minami, H. Kimura and Y. Ihara, Mater. Sci. Tech., 9, 795 (1986).

28. W.G. Johnson and J.J. Gilman, J. Appl. Phys., 30, 129 (1959).

29. J.C.M. Li, Acta Metall., 11, 1269 (1963).

30. N.S. Akulov, Acta Metall., 12, 1195 (1964). 
